\title{
Perspectivas de la vacuna contra el VIH.
}

\author{
CERVANTES GONZALES, Jorge Luis*, AGUILAR OLANO, José*
}

Para algunos pacientes, hoy en día la infección por el virus de inmunodeficiencia humana (VIH) se está convirtiendo (al menos temporalmente) en una condición médica manejable, debido a las nuevas y potentes combinaciones de medicamentos antiretrovirales, que incluye inhibidores de proteasa. Sin embargo, estas nuevas combinaciones están muy lejos de resolver el problema tanto a nivel individual como de Salud Pública, debido a que estas asociaciones no van a ser exitosas en todos los casos, porque es dificil el cumplimiento de una terapia que incluye la administración de varias decenas de pastillas al día, y finalmente porque el costo está lejos de estar al alcance de la mayoría de pacientes $(1,2)$.

A pesar de que la educación para modificar las conductas de riesgo para evitar el contagio es un pilar básico en el control de esta pandemia, la historia nos ha enseñado que una vacuna es la forma más efectiva de tratar con una enfermedad de esta magnitud (cerca de 7,500 adultos y1000 niños se infectan cada día con el VIH) Con una tasa tan alta de expasión, la prevención es siempre menos costosa que el tratamiento. Las intervenciones en educación sexual y uso del condón, han tenido un éxito considerable, pero no han logrado detener la diseminación del VIH. La abstinencia sexual o el uso de métodos de barrera, resultan impracticables para muchas personas; más ún en sociedades como la nuestra donde existe una gran proporción de la población con conductas socialmente aceptadas y que son reconocidas como conductas de riesgo (3).

La vacuna ideal, por el contrario, sería eficiente, de fácil administración, y brindaría protección duradera (1). Comúnmente pensamos en vacunas como preventoras de infección, producido una inmunidad "esterilizante". Sin embargo, no todas las vacunas funcionan bajo esta mecánica y de hecho relativamente pocas vacunas previenen la infección en las células del hospedero.

Otras vacunas más bien, confieren protección, reduciendo la carga inicial del patógeno, acelerando la "depuración " de la infección, o previniendo la recurrencia, secuelas , o transmisión. Una vacuna para el SIDA, incluso parcialmente protectora (con una efectividad del 20 a 40\% de la efectividad de la vacuna del polio o el sarampión), salvaría y prolongaría millones de vida, y reduciría la transmisión secundaria a la descendencia y contactos. El uso público de una vacuna se decide entonces, no sólo por su eficacia, sino tambien por la magnitud y urgencia del problema ( el número de personas infectadas con VIH continúa incrementándose a nivel mundial, con cálculos matemáticos que subestiman el número real de nuevos infectado ) $(2,4)$. 
Dificultades en el desarrollo de la vacuna para VIH.

Se están llevando a cabo grandes esfuerzos para desarrollar vacunas que prevengan o modifiquen el curso de la infección por VIH.

El desarrollo y la evaluación de vacunas para VIH, se ha visto obstaculizada por varios factores: i) la carencia de un total entendimiento de los eventos inmunológicos ocasionados por la infección y los mecanismos inmunes asociados a protección contra la infección por VIH, y ii) la falta de modelos animales que simulen la infección y enfermedad ( los retrovirus tiene la característica de ser especie- específicos) $(3,5)$.

Pocas compañías se han interesado en el desarrollo de una vacuna preventiva de VIH, debido a que el costo sería alto, y los beneficios estarían limitados por la pobreza de los países en desarrollo, que es donde la vacunación masiva más se necesita $(1,6)$

Aún asi, los estudios de vacunas de VIH en primates (chimpancés) y voluntarios humanos, y vacunas para prevenir la infección por el virus de inmunodeficiencia del simio (VIS) ( como un posible modelo para las vacunas de $\mathrm{VIH}$ ), en pocos casos han progresado a fase II (5).

Los ensayos clínicos en humanos tiene tres fases. Los estudios en fase I, involucran un número pequeño de personas, evalúan la seguridad y tolerancia de dosis de vacuna en aumento, y proveen alguna información concerniente a inmunogenicidad. Los ensayos en fase II, son ensayos que incluyen a individuos en riesgo, y busca determinar la habilidad de una vacuna para inducir protección. Los ensayos en fase III son ensayos a gran escala de eficacia y seguridad en individuos en riesgo, en el que el número de personas requeridas se determina por el riesgo anual de infección o enfermedad, la eficacia estimada de la vacuna, y la duración del ensayo clínico. Mientras más grande sea el ensayo, más costoso será éste (2).

El desarrollo de una vacuna efectiva enfrenta una serie de ostáculos:

- Carencia de entendimiento acerca de la inmunidad protectiva contra el VIH.

- Extrema variabilidad en la secuencia del virus, resultados de mutaciones y recombinaciones, que suceden en un mismo individuo infectado.

- Replicación rápida y persistente del virus, Incluso durante el periodo de aparente latencia clínica. Durante esta latencia se produce una activa replicación,
Tabla $\mathbf{N}^{\circ} 1$. Dificultades en el desarrollo de una vacuna contra el VIH.

- Carencia de entendimiento acerca de la inmunidad protectiva contra el VIH.

- Extrema variabilidad en la secuencia del virus, resultado de mutaciones y recombinaciones.

- Replicación rápida y persistente del virus.

- Ausencia de modelos animales debido a que los retrovirus son especie-específicos.

- El logro de inmunidad persistente podría requerir expresión permanente de la vacuna.

- Vacunas en base a virus vivos atenuados podrían recombinar con virus silvestres y revertir a formas virulentas.

- Posibilidad de que una vacuna pudiera inducir cuadros de autoinmunidad.

- Sujetos vacunados serían serológicamente positivos para VIH (es decir, presentarían anticuerpos contra el VIH) con las dificultades legales, laborales (así como seguros de vida, viajes internacionales, etc.), que esto implicaría (10).

principalmente en células dendríticas de ganglios regionales. (La infección puede estar presente varios meses antes de que puedan detectarse anticuerpos contra el VIH) $(7,8)$.

- El logro de una inmunidad persistente podría requerir una expresión permanente de la vacuna.

- En el caso de utilizar vacunas en base a virus vivos atenuados, éstos podrían recombinar con virus silvestres y revertir hacia una forma virulenta (9). (Ver Tabla $\mathrm{N}^{\circ} 1$ ).

El VIH es un virus con una alta tasa de variación de regiones antigénicamente estratégicas, existe variación genética significativa en un mismo individuo infectado.

La extrema variabilidad de la secuencia del VIH ocasiona un severo problema al sistema inmune. Las altas tasas de replicación, mutación, y recombinación del VIH le permiten escapar a la respuesta inmune natural o aquella evocada por una vacuna (9).

Existen además otras dificultades técnicas en la investigación del VIH, como la carencia de un modelo animal ideal, la existencia de múltiples subtipos de VIH y dificultades en la inducción de inmunidad en las mucosas, entre otras.

\section{Posibilidades de desarrollo de una vacuna para VIH.}

No obstante todas estas dificultades, existen algunas razones para creer que sí es posible el desarrollo de una vacuna para el VIH.:

- La vacunación ha sido exitosa contra otras enfermedades virales, como polio, sarampión, paperas, rubeola, influenza, rabia, hepatitis A y B. 
- Vacunas experimentales han protegido a simios del virus de inmunodeficiencia del simio (VIS). En particular, la atenuación del VIS debido a una supresión del segmento nef y otras secuencias del gen viral, han resultado en protección de simios a pesar de la administración repetida de altas dosis de VIS virulento (11).

- Vacunas candidatas han logrado inducir respuestas inmunes considerables en humanos. Varias vacunas candidatas han logrado desarrollar niveles altos de anticuerpos neutralizantes (control cepas de laboratorio), o linfocito $\mathrm{T}$ citotóxicos especificos para el VIH (12), que son dos de los principales mecanismos implicados en el bloqueo de la invasión viral a las células humanas y en la destrucción de células infectadas y por lo tanto en la eliminación del virus.

- En algunos casos los humanos pueden regular la replicación del VIH parcial o temporalmente.

Ejemplo de esto, son los sobrevivientes de larga data $(5-10 \%$ de adultos y niños infectados, que permanecieron sanos por 12 años o más, con cargas virales menores a 1000 copias de RNA/mL)(1).

Estos individuos infectados "no progresivos" aparentemente representan un grupo heterogéneo, en el que algunos se encuentran infectados con cepas de VIH no patógenos o menos virulentas, y otros parecen poseer respuestas inmunes suficientemente efectivas para mantener o al menos prolongar la fase clínica latente de la infección por VIH (13). La carga viral es generalmente menos en los " no progresivos" que en los individuos que presentan progresión rápida (aproximadamente 10\% de individuos infectados que progresan a al esatadío SIDA dentro de los primeros 2 a 3 años de la infección). Es importante la determinación de respuestas de linfocitos $\mathrm{T}$ citotóxicos y de anticuerpos neutralizantes protectivos en los "no progresivos", para un entendimiento de la base biológicas del estado de "no progresión y el diseño de vacunas efectivas (13).

- Existen también unos cuanto casos documentados de neonatos, quienes erradicaron completamente la infección sin el uso de terapia farmacológica; al igual que algunos casos de prostitutas y adultos de riesgo, quienes a pesar de haber estado expuestos repetidamente, estuvieron infectados sólo transitoriamente.

El virus ingresa a las células CD4 via complejos gp120-
CD4(14). Pero recientemente se ha descrito varios receptores para beta-quimioquinas como coreceptores para el VIH $(14,15,16)$. Los receptores CCR5 ( previamente descrito CCKCR5) y CCR4 y otros para beta-quimioquinas han sido descrito como coreceptores para el VIH.

- Algunas personas permanecen sin infectarse a pesar de exposición repetida al virus, debido a una ausencia de 32 pares de bases en el gen que codifica al receptor CC5, que media el ingreso del virus en los macrófagos y células CD4 activadas. En homocigotes, esta mutación parece conferir protección completa contra la infección, mientras que en heterocigotes está asociada a cargas virales bajas, y retraso de la progresión de la enfermedad.

- Adultos infectados con VIH atenuado han permanecido sanos. Hace catorce años, un grupo de hombres y mujeres en Sydney, Australia, resultaron infectados luego de recibir productos sanguíneos $u$ órganos de un donante infectado con un VIH que luego se encontró, tenía secuencias ausentes importantes en el gen nef. Estos individuos, incluyen al donante, permanecieron sanos o fallecieron de causas diferentes al SIDA.

- La transmisión del VIH a través de las mucosas es relativamente ineficiente. El hecho de que la probalidad de transmisión del VIH es pequeña para cada relación sexual, sugiere la existencia de barreras naturales, las cuales podrían aumentarse con una vacuna que induzca suficientes respuestas humoral y celular.

- La disminución de la carga viral viral con drogas antiretrovirales, brinda beneficio clínico.

Lo que sugiere que una vacuna exitosa no necesita bloquear la infección completamente; bastaría con que logre una rápida " depuración " o reducción de la carga viral a un punto en el que no produzca síntomas o permita la transmisión (1).

La vacuna ideal debe ser, segura, de fácil administración, barata, estable, debe proteger contra todos los subtipos de VIH, y debe requerir sólo pocas dosis para brindar protección permanente (1). La meta global de cualquier estrategia de inmunización es inducir una respuesta inmune especifica (contra el patógeno), que sea potente y duradera, con el mínimo número de inmunizaciones (17).

\section{Diseños actuales de vacunas contra VIH.}

\section{Diseños con proteína de envultura.}

El ataque por el VIH a las células T involucra la unión de la glicoproteína viral gp 120 al receptor CD4, luego 
de esta unión se produce la fusión del virus y la células (primera etapa de la replicación viral). Debido al rol crucial que juega esta subunidad gp 120, se la utilizó desde hace varios años para generar anticuerpos neutralizantes contra el VIH-1.

Estos fueron los primeros candidatos debido a que las proteínas de la envultura eran el sitio principal donde se dirigían los anticuepos neutralizantes, y este diseño había resultado exitoso en el caso de la hepatitis B. Desafortunadamente, los recombinantes de gp120 eran monómeros solubles, y no agregaban como los recombinantes de la hepatitis $\mathrm{B}, \mathrm{y}$ su inmunogenicidad era limitada (1).

Existe evidencia de que anticuerpos neutralizantes pueden proteger contra la infección por VIH en algunos modelos animales (18). Sin embargo se requieren de altas concentraciones de anticuepos, y de anticuerpos de gran especificidad para que sean efectivos (19).

Varias vacunas de gp 120 monoméricas han sido probadas en humanos. Una ventaja de estas proteínas es su habilidad para inducir anticuerpos contra los epítopes que rodean al sitio de unión del CD4-(20), y por lo tanto evitar el ingreso a la célula humana.

Realizando un mapeo de epitopes de VIH en linfocito $\mathrm{B}$, utilizando predicciones a partir del análisis de secuencias, se ha encontrado que cerca de 11 sitios en la secuencias de env pueden ser reconocidos por los linfocitos B. En la práctica 4 epítopes de gp 120 y 5 de gp 41 son reconocidos por los linfocitos B. En la práctica 4 epítopes de gp 120 y 5 de gp 41 son reconocidos por linfocitos $\mathrm{B}$, estos son epítopes relativamente conservados (o sea con poca variabilidad antigénica) en diversas cepas, y pueden mostrar regularidad para unir anticuerpos de suero de pacientes infectados, indicando su antigenicidad en vivo. Los anticuerpos contra oligopéptitidos sintéticos, conteniendo las secuencias de aminoácidos definidas por estos sitios, seria biológicamente activos. Estudios de los anticuerpos naturales y aquellos contra oligopéptidos sintéticos, han localizado un sitio específico, una estructura en asa, llamada V3, en la región variable del env gp120. Es interesante también que este sitio esta indentificado con un epítope del linfocito $\mathrm{T}$, y es un sitio dominante para los anticuerpos neutralizantes (21). Sin embargo en la práctica anticuerpos contra proteínas de envultura no han mostrado buenos resultados.

$\mathrm{Al}$ inicio de los 90, se observó que varias vacunas desarrolladas en Genentech, Chiron, Micro Genesys, e ImmunoAg, a partir de componentes de la envultura del VIH (ya sea bien la gp120, o su precursor gp160), estimulaban la producción de anticuerpos capaces de neutralizar cepas de laboratorio de VIH. En 1994, se observó que estos anticuerpos no eran eficaces de neutralizar cepas de VIH pacientes infectados $(1,20,22)$.

Se han descrito en la literatura el caso de 18 voluntarios, quienes se infectaron con VIH-1 mientras tomaban parte de un estudio en fase II de dos vacunas recombinantes de subunidad gp 120 (23). Al igual que en otro caso único descrito (24), en el que a pesar de haberse administrado el total de inmunizaciones, el individuo resultó infectado cuando su respuesta inmune se encontraba en su nivel pico (25).

Una posible explicación de por qué fallan estas vacunas, es que los sujetos se infecten con cepas de VIH-1 que posean proteínas de envultura diferentes a aquella de la vacuna en varios sitios susceptibles de neutralización por anticuerpos (20).

Experimentos realizados con un anticuerpos monoclonal humano (F105) dirigido contra un epítope cercano al sitio de unión del receptor CD4, no sólo falló en neutralizar al VIH-1, sino por el contrario incrementa su infectividad (26).

No existe evidencia de que el incremento de la infectividad mediada por anticuerpos tipo F105 contribuya a una falta de actividad de las vacunas de gp120 monoméricas, pero debe considerarse esta posibilidad, Se ha encontrado que suero de personas infectadas con títulos altos de anticuerpos anti-gp120, incrementa débilmente la infectividad de la cepa primaria de VIH-1; otros sueros carecen de la actividad de neutralizar, Tal vez estos anticuerpos tipo F105, contribuyan a este efecto al contrarrestar, parcial o totalmente, anticuerpos neutralizantes presentes (20).

VaxGen, una compañía de Biotecnología de California liderada por Donald Francis, uno de los pioneros en la investigación del SIDA, iniciara este año el primer ensayo clínico a gran escala en humanos de la controversial vacuna de gp120 (AIDSVAX)(27), luego de obtener la aprobación por la FDA $(28,29)$. Este ensayo clínico en fase III, cuyo costo asciende a los 20 millones de dólares, tendrá una duración de tres años e involucra a 7,500 voluntarios años de los Estados Unidos y Tailandia (28). La vacuna consiste en un recombinante de gp 120con un adyuvante de alúmina (24)

Diseños con péptidos. Más simple y menos costosos, podían unirse a transportadores lipídicos para provocar respuestas T citotóxicas y administrarse oralmente. Sin embargo, resultaron ser muy poco inmunógenos, y 
requerían dosis muy altas para inducir respuestas humorales que eran de poca afinidad.

Vectores con virus Vacuna vivo. El uso de virus de la vacuna atenuado (enfermedad histórica de donde se origina el nombre de vacunación) fue uno de los primeros candidatos en ser evaluado en humanos. Administrado sólo, no inducía considerablemente la formación de anticuerpos, pero administrado luego de aplicarse una serie de monómeros solubles, de gp120, el producto inducía niveles altos de anticuerpos en un porcentaje significativo de los individuos. Hubo preocupación de que el virus atenuado (a pesar de no producir efectos inusuales en los individuos sanos) podría no ser seguro en poblaciones de alto riesgo; por ello estas vacunas no fueron más allá de la fase I.

Vectores con virus Avipox. Vectores vivos recombinantes (tales como el avipox, canarypox) constituyen estrategias importantes y prometedoras (19). El virus canarypox, miembro de la familia del virus vacuna, expresa proteínas en celulas humanas, perono entra en un ciclo de replicación completo, Por ello, la seguridad no era una preocupación como en el caso anterior, y al igual que este, al ser administrado sólo inducía poca formación de anticuerpos, pero siguiendo un curso de una o dos administraciones de gp 120, se lograba la formación de anticuerpos neutralizantes en un porcentaje elevado de los individuos. Una version nueva (ALVACvCP205), consistente en un virus vector canarypox que expresa el env, gag y proteasa del VIH, seguido de un boost de gp 120 está entrando a fase II. Se espera que este tipo de vacunas entren a ensayos en fase III en 1999 o el año 2000 (1).

Otros vectores virales incluyen un adenovirus que expresa gp 160, vectores de poliovirus, virus de influenza, mengovirus, y virus vector de encefalitis equina venezolana (deberán tenerse en cuenta los riesgos que acarrea el uso de estos vectores).

Vectores bacterianos en investigación incluyen Salmonella typhi atenuada, bacilo Calmette-Guerin (BCG), y Listeria monocytogenes atenuada.

\section{Vacunas vivas atenuadas}

Históricamente, muchas vacunas exitosas fueron hechas a partir de virus vivos atenuados a virus "muertos". Sin embargo, ambas estrategias son problemáticas para el caso del VIH.

Los virus atenuados podrían ser efectivos, pero existe una lógica preocupación sobre la seguridad de éstos (19).Ninguna de esta clase ha sido evaluada en humanos debido al riesgo de que estos virus atenuados puedan revertir a formas virulentas (1) (lo cual sería más peligroso en individuos inmunocomprometidos).

El uso de cepas atenuadas de VIH como vacunas permanece controversial. Cepas atenuadas de VIS han protegido a monos rhesus adultos contra un reto de VIS (11),y una infección con VIH-2 puede conferir alguna protección contra VIH-1 en humanos (30). Sin embargo VIS vivos atenuados (con eliminación del gen nef), que no son patógenos en monos rhesus adultos, podrían serlo para animales neonatos (31). Los individuos naturalmente infectados con virus de VIH-1 portadores de eliminación del gen nef, no han erradicado el virus de sus organismos (32). La razón de esto es aún una interrogante.

Tan controversiales como las vacunas vivas atenuadas, son los diseños que utilizan particular de VIH inactivadas. El 100\% de la inactivación no puede ser verificada sino inoculando un gran número de personas(y exponiéndolos a la infección )(1).

Un diseño diferente consiste en la creación de partículas conteniendo todos o una gran proporción de epítopes de gag. Estos pseudoviriones contienen la envultura (gp120, gp160) y gag (p55,p24) (PasteurMerieux Connaught), y probablemente entren a fase I en los Estados Unidos este año.

Vacunas de DNA. Las vacunas de DNA contiene el gen o los genes que codifican una porción antigénica del virus, tales como proteínas del núcleo o de la envoltura. Las células del hospedero toman el DNA, expresan el gen viral, y producen la proteína viral correspondiente dentro de la célula $(33,34)$. Una ventaja importante de este sistema es que la proteína viral ingresa a la via del complejo mayor de histocompatibilidad (MHC) de clase I. Las moléculas del MHC de clase I llevan fragmentos de la proteína viral a la superficie de la célula, evocándose inmunidad mediada por células al estimularse células T CD8 citotóxicas. Por el contrario, antígenos de vacunas standard son tomados por la células via fagocitosis o endocitosis, y son procesados a través del sistema de MHC clase II, el cual (vía presentación a linfocitos CD4) estimula primariamente la respuesta de anticuerpos (30) (Figura $N^{\circ} 1$ ).

El genoma del VIH consta de los genes env, gag, pol 2 genes reguladores (tat y rev) y 4 genes accesorios (vit, vpr,vpu y nef) (Figura $\mathrm{N}^{\circ}$ 2). El gen env codifica para las proteínas exteriores de envultura viral. El gen gag codifica para la proteína núcleo, y el pol codifica para las proteínas enzimáticas transcriptasa reversa (RT), integrina (Int) y proteasa (Pro). Los genes reguladores 


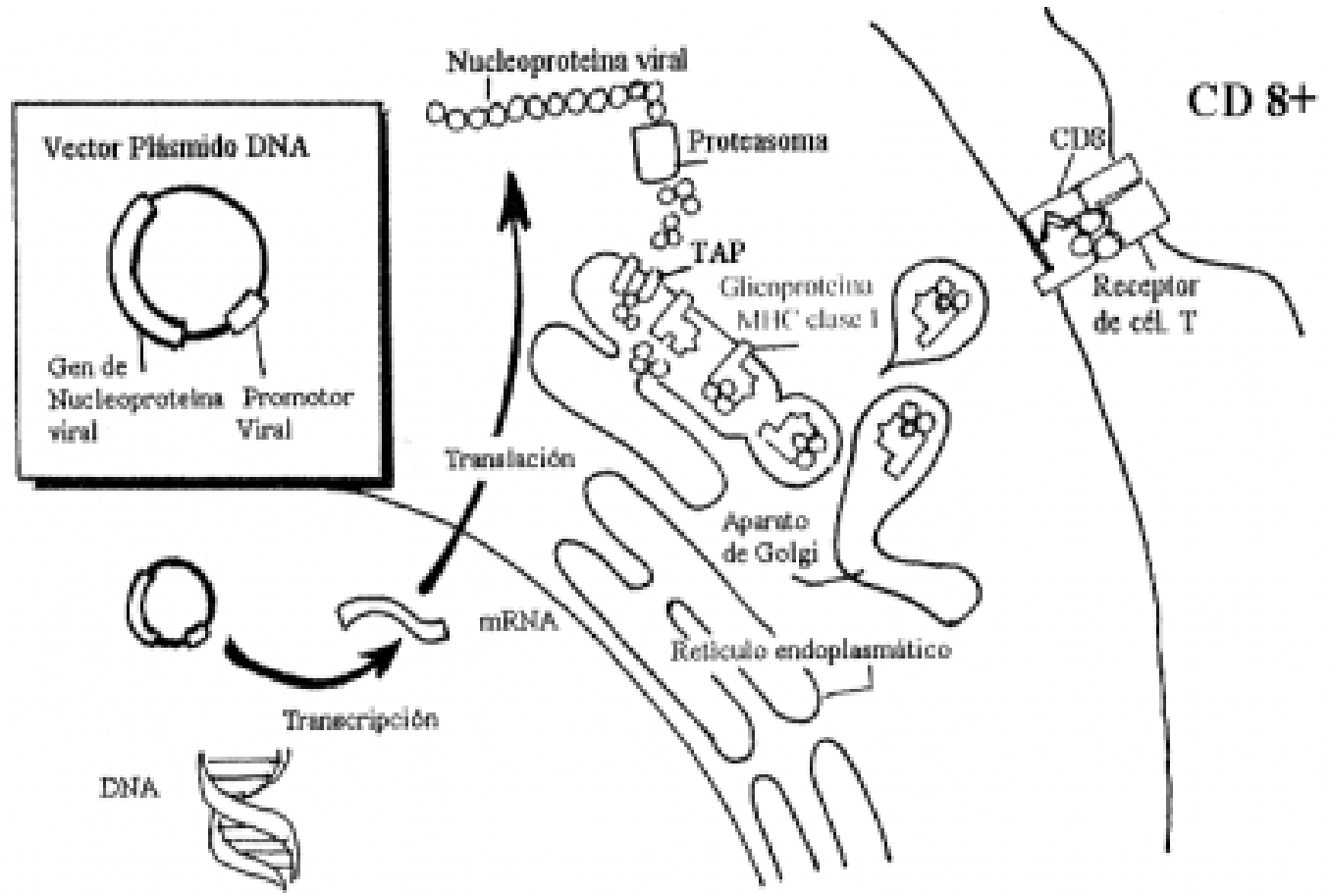

Figura Nol. Ruta de una vacuna de DNA. (Modificado de MrDonell WM, Askari FK. Molecular medicine. DNA vaecines. New England Journal of Medicine 1996; $334: 42-45)$.

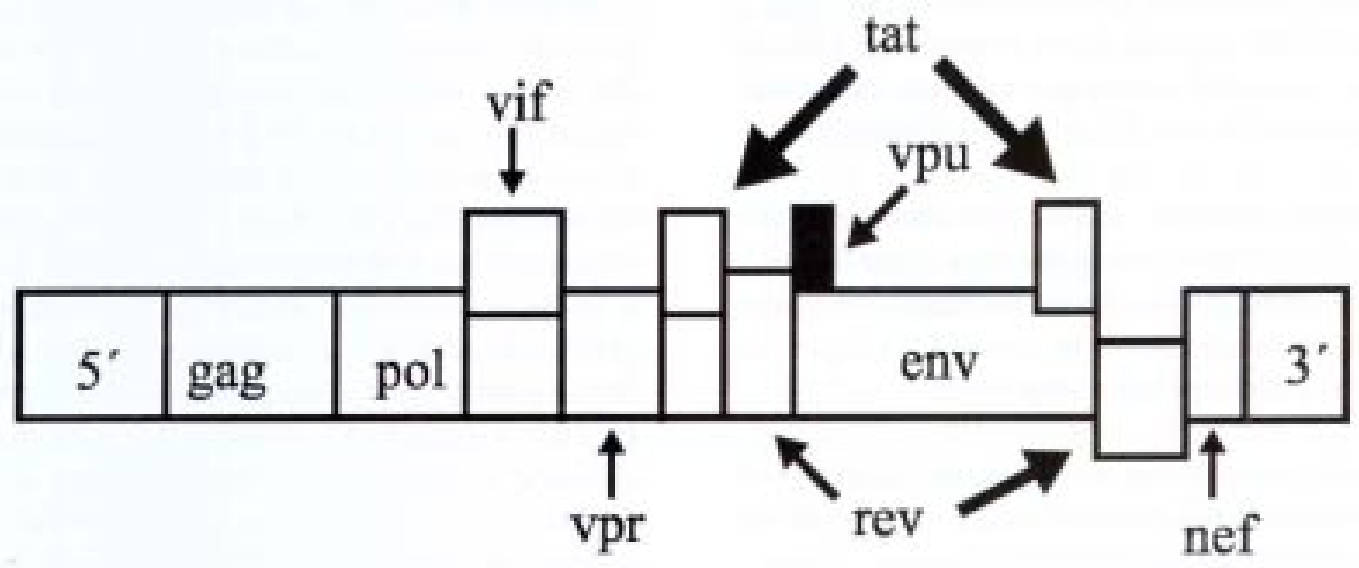

Figura $\mathrm{N}^{\circ}$. $\quad$ Genoma del VIH mostrando los genes blanco potenciales para inmunización con vacunas de DNA.

$(\mathrm{vif}=$ virion infectivity factor; $\mathrm{vpr}=$ viral protein $\mathrm{r} ; \mathrm{vpu}=$ viral protein $\mathrm{u}$; nef $=$ negative factor) 
tat y rev afectan la expresión del gen del VIH integrado al genoma de la célula hospedera La transcripción se incrementa varios cientos de veces debido al tat, por ello esta región es un blanco obvio para intervenciones terapeúticas. El gen rev es un componente crítico en la producción de proteínas estructurales del VIH-1, y respuestas inmunes dirigidas contra la región rev interferirán con el ciclo de vida viral (17).

Además de los genes reguladores, el VIH-1 posee un grupo de genes accesorios (vif, vpf, vpu y nef) que son blancos potenciales para inmunización con DNA, por ejemplo, experimentos realizados con VIS en monos rhesus infectados con virus que portaban una deleción del nef, tenían niveles bajos de replicación viral (11).

Las vacunas de DNA son seguras y menos costosas en comparación con las proteínas recombinantes, son diseños potencialmente altamente inmunogénicos, (habiendo desencadenado respuestas humorales y $\mathrm{T}$ citotóxicas CD8 de memoria, en modelos animales).

Pueden administrarse oralmente, lo cual garantizaría la inducción de respuesta inmune en mucosas (17).

Estudios en humanos de vacunas de DNA incluyen aquellos dirigidos por R.R. Mac Gregor en la Universidad de Pennsylvania, que evalúa una vacuna de DNA env/rev, en pacientes infectados; aquí 15 voluntarios seropositivos cal VIH- 1 recibieron 3 inyecciones de dosis crecientes de vacuna, con intervalos de 10 semanas, desarrollando los individuos un aumento en anticuerpos contra proteínas de envoltura y otros péptidos estructurales, e incluso se observaron algunas respuestas celulares aumentadas (17).

Al momento, vacunas candidatas basadas en ácidos nucleicos (producidas por Apollon), expresando VIH env, o VIH gag, pol y env han entrado a ensayos fase I (1). AVEG ha iniciado un ensayo en Fase I de una vacuna de DNA gag/pol. J.Kovacs del Instituto Nacional de Salud Norteamericano (NIH) dirige un estudio de una vacuna de DNA profiláctica; este estudio es importante pues representa la primera vez que se aprueba terapia genética para ser evaluada en individuos sanos (17).

Las vacunas de DNA descritas, casi en su mayoría se basan en el subtipo B, que es el subtipo prevalente en los Estados Unidos, Europa y en el Perú. Pero la demanda de una vacuna es alta en los Países en desarrollo, donde otros subtipos son prevalentes (A,C,D en Africa, C en India, $\mathrm{E}$ en Asia )(1). Aunque recientemente se reconoce cada vez mas 2 a 3 cepas en cada región.

El camino hacia encontrar una vacuna para el VIH está en ascenso. A medidad que se conoce más cerca de la respuesta inmune, y de las vacunas candidatas, nos acercamos más hacia la meta.

\section{Correspondencia:}

Dr. José Aguilar Olano.

Laboratorio de Inmunodiagnóstico. Universidad

Peruana Cayetano Heredia Av. Honrio Delgado 430

SMP.E-mail: jaguilar @ upch.edu.pe

\section{BIBLIOGRAFIA}

1. Margaret IJ.HIV Vaccines : Problems and Prospects. Hospital Practice 1997; 3: 125-140.

2. Barry RB. A Perspective on AIDS Vaccines. Science 1996; 272:888-90

3. Aguilar J.L.: Biología e Inmunología del VIH. En Sánchez J, Gotuzzo E, Cuéllar L, Mazzoti G. SIDA. Epidemiología, Diagnóstico, Tratamiento y Control de la Infección VIH/ SIDA. Lima Perú. 1994. p: 33-55.

4. Holden C: World AIDS- The worst is still to come. Science 1997; 278-1715.

5. Collier L, Balows A, Sussman M. Topley \& Wilson's Microbiology and Microbial Infections. Vol 1 Virology. 9.2. Human inmunodeficiency virus vaccines 1998; 984985.

6. Cohen J. The Marketplace of HIV/AIDS. Science 1996; 272: 1880 .

7. Imagawa DT et al. Human Immunodeficiency Virus type 1 infection in homosexual men who remain seronegative for prolonged periods. N Engl J Med 1989; 320: $1458-62$.

8. Levy JA. Pathogenesis of Human Immunodeficiency Virus Infection. Microbiol Rev 1993; 57: 183-289.

9. Banham C, Phillips RE, what is required of an HIV vaccine? Lancet 1997; 1350: 1617-21.

10.Graham BS, Wright PF, Candidate AIDS Vaccines. N Engl J Med 1995; 333: 1331-39.

11.Daniel M.D., et al. Protective Effects of a Live Attenuated SIV Vaccine with a Deletion in the nef Genescience. 1992; 258:1938-41.

12.Oldstone MB. HIV versus cytotoxic T lymphocytes-The war being lost. N Engl J Med 1997; 337: 1306-1308.

13.Haynes B.F., Pantaleo G, Fauci A. Toward an Understanding of the Correlates of Protective Immunity to HIV infection. Science 1996; 271: 324-328.

14.D'Souza MP, Harden VA.Chemokines and HIV-1 second receptors. Confluence of two fields generates optimism in AIDS Research. Nature Medicine 1996; 2: 1293.

15.Samson M, Libert F, Doranz BJ, et al. Resistance to HIV1 infection in caucasian individuals bearing mutant alleles of the CCR-5 chemokine receptor gene. Nature 1996; $382 ; 722-25$.

16. Liu R, et al. Homozygous defect in HIV-1 corecptor accounts for resistance of some multyply-exposed individual to HIV-1 infection. Cell 1996; 86: 367-77.

17.Kim JJ, Weiner DB. DNA gener vaccination for HIV. Springer Semin Immunopathol 1997; 19: 175-194. 
18.Burton D.R., A vaccine for HIV type 1: the antibody perspective. Proceedings of the National Academy of Science USA 1997; 10018-10023.

19.Birton DR, Moore JP. Why do we not have an HIV vaccine and How can we make one? Nature Medicine Vaccine Supplement. 1998; 4; 495-98.

20.Moore JP. HIV Vaccines. Back to primary school. Nature 1995; 376: 115.

21.Collier L, Balows A, Sussman M. Topley \& Wilson's Microbiology and Microbial Infections. Vol. 1 Virology 7.3 Prospects of vaccine development1998,801.

22.Graham BS, McElrath MJ, Connor IR, et al. Analysis of Intercurrent Human Immunodeficiency Virus Type 1 Infections in Phase I and II Trials of Candidate AIDS Vaccines. J Infect Dis 1998; 177: 310-9.

23.Connor, R. I. et al. Immunological and virological Analysis of Persons Infected by Human Immunodeficiency Virus Type 1 while participating in Trials of Recombinant gp 120 Subunit Vaccines. J Virol 1998; 72: $1552-1576$.

24.Kahn, J. et al. Clinical, Immunological, and Virologic Observations Related to Human Immunodeficiency Virus (HIV) Type 1 Infection in a Volunteer in an HIV1 Vaccine Clinical Trial. J Infect Dis 1995; 171: 13431347.

25.Bolognesis DP, Matthews TJ. Viral envelope fails to deliver. Nature 1998; 391: 638-39.

26.Sullivan $\mathrm{N}$ et al. Replicative Function and Neutralization Sensitivity of Envelope Glycoproteins from Primary and T-Cell Line-Passaged Human Immunodeficiency Virus type1 Isolated. J Virol 1995; 69: 441322.

27.AIDSVAX Trials http://www.vaxgen.com/vaccine .htm

28.Go-ahead given for trials of HIV vaccine in human volunteers. Nature 1998; 391: 220.

29.Balter m. Impending AIDS Vaccine Trial Opens Old Wounds. Science 1998; 279-650.

30.Travers K, et al. Natural Protection Against HIV-1 Infection Provided by HIV-2 Science 1995; 268: 1612 15.

31.Baba T.W., et al., Pathologenicity of Live Attenuated SIV After Mucosal Infection of Neonatal Macaques. Science 1995; 267: 1820-25.

32.Deacon N.J, et al. Genomic structure of an attenuated quasi species of HIV-1 from a blood transfusion donor and recipients. Science 1995; 270: 988991.

33.McDonnell M, Askari FK. Molecular Medicine DNA vaccines. N Engl J Med 1996; 334: 42-45.

34.Cohen IR, Steinman L. Exploring the Potential of DNA Vaccination. Hospital Practice 1997; 3: 169-178. 